

HTTP://DX.DOI.ORG/10.22256/PUBVET.V11N3.306-312

\title{
Razão valina com lisina em rações para codornas japonesas em postura
}

\author{
Eriane de Paula ${ }^{1 *}$, Sergio Luiz de Toledo Barreto ${ }^{2}$, Renata de Souza Reis ${ }^{3}$, Regina Tie \\ Umigi $^{1}$, Heder José D'Avila Lima ${ }^{5}$, Dayana Cristina Oliveira Pereira ${ }^{6}$
}

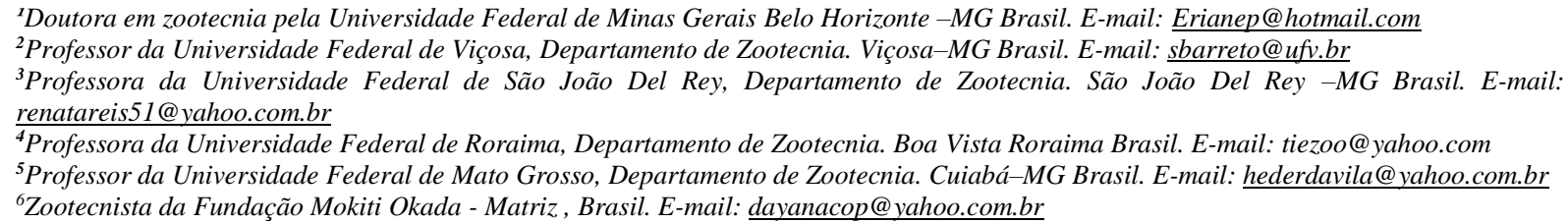

RESUMO. Foi conduzido um experimento no Setor de Avicultura do Departamento de Zootecnia da Universidade Federal de Viçosa - UFV, objetivando-se estabelecer a razão de valina digestível com lisina digestível em rações para codorna japonesa na fase de postura. Foram utilizadas 480 codornas com idade inicial de 284 dias. As aves foram distribuídas em delineamento experimental inteiramente casualizados com seis tratamentos, dez repetições e oito aves por unidade experimental. Os tratamentos consistiram de uma ração basal deficiente em valina, com 18,6\% de proteína bruta e 2900 $\mathrm{kcal}$ de EM/kg, suplementada com cinco níveis de L-valina $(0,051 ; 0,101 ; 0,151 ; 0,202 \mathrm{e}$ $0,252 \%$ ) em substituição ao ácido glutâmico, em equivalente proteico, correspondendo às relações de valina digestível com lisina digestível de 0,$75 ; 0,80 ; 0,85 ; 0,90 ; 0,95 ; 1,00 \%$, respectivamente, permanecendo as rações isoproteicas e isocalóricas, sendo a lisina digestível fixada em 1,00\%. Os parâmetros estudados foram: consumo de ração (g/ave/dia), produção de ovos por ave dia (\%), produção de ovos comercializáveis (\%), peso do ovo (g), massa de ovos (g/ave/dia), conversão alimentar por massa de ovos (kg de ração/kg de ovos), conversão alimentar por dúzia de ovos (kg de ração/dz de ovos), variação do peso corporal (g), peso dos componentes (g) e percentagem dos componentes dos ovos (gema, albúmen e casca) e gravidade específica $(\mathrm{g} / \mathrm{cm} 3)$. Não foram observadas mudanças significativas nos parâmetros avaliados em função das diferentes relações de valina com lisina digestível estudadas. Concluiu-se que a razão de valina digestível com lisina digestível de 0,75 na ração, proporciona resultados satisfatórios de desempenho e de qualidade de ovos para codornas japonesas em postura.

Palavras-chave: Aminoácido, codorna japonesa, produção de ovos, valina

\section{Ratio of valine to lysine in diets for laying Japanese quail}

ABSTRACT. To determine the relationship valine to lysine for Japanese quails during the period of production, it was conducted an experiment in DZO-UFV using 480 subspecies Japanese quails (Coturnix coturnix japonica) with, 284 days of age. The birds were distributed in a completely randomized design with six treatments (relationships of valine to lysine), ten replicates and eight birds per experimental unit. The treatments consisted of a basal diet deficient in valine with $18.6 \%$ crude protein and $2900 \mathrm{kcal}$ metabolizable energy $/ \mathrm{kg}$, supplemented with five levels of L-Valine $(0.051,0.101,0.151,0.202$ and $0.252 \%$ ) corresponding to the ratio of valine to lysine of $0.75 ; 0.80,0.85,0.90,0.95$ and $1.00 \%$ respectively, and the lysine set at $1.00 \%$. The variables studied were: feed intake (g/bird/day), egg production per bird day (\%), production of commercial eggs (\%), egg 
weight (g), egg mass ( $\mathrm{g} / \mathrm{bird} /$ day), feed conversion by egg mass ( $\mathrm{kg} \mathrm{feed} / \mathrm{kg}$ egg), feed per dozen eggs ( $\mathrm{kg}$ feed/dz of eggs), weight of components (yolk, albumen and shell), percentage of eggs components and specific gravity $\left(\mathrm{g} / \mathrm{cm}^{3}\right)$. There was no significant effect in the parameters evaluated in terms of ratio of valine to lysine studied. The relationship of valine to lysine in the ration of 0.75 provides satisfactory performance and eggs quality of Japanese quail.

Keywords: Amino acid, egg production, Japanese quails and valine

\section{Relación de valina y lisina en las dietas de codornices japonesas}

RESUMEN. Fue realizado un experimento en el Sector de Avicultura del Departamento de Zootecnia de la Universidad Federal de Viçosa con el objetivo de establecer la relación de valina digestible con lisina digestible en dietas para codornices japonesas en la fase de postura. Fueron utilizadas 480 codornices con edad inicial de 284 días. Las aves fueron distribuidas en diseño experimental completamente al azar con seis tratamientos, diez repeticiones y ocho aves por unidad experimental. Los tratamientos consistieron en una dieta basal deficiente en valina, con $18,6 \%$ de proteína bruta y $2.900 \mathrm{kcal}$ de EM/kg, suplementada con cinco niveles de L-valina $(0,051 ; 0,101 ; 0,151 ; 0,202$ y $0,252 \%)$ en sustitución al ácido glutámico, en equivalente proteico, lo que corresponde a las relaciones con valina digestible de 0,$75 ; 0,80 ; 0,85 ; 0,90 ; 0,95 ; 1,00 \%$, respectivamente, permaneciendo las dietas isoproteicas e isocalóricas, siendo la lisina digestible fija en 1,00\%. Los parámetros estudiados fueron: consumo de alimento (g/ave/día), producción de huevos por ave día (\%), producción de huevos comercializables $(\%)$, peso del huevo $(\mathrm{g})$, masa de huevos (g/ave/día ), conversión alimenticia por masa de huevo (kg de alimento/kg de huevos), conversión de alimento por docena de huevos ( $\mathrm{kg}$ de alimento/dz huevos), variación del peso corporal (g) peso de los componentes (g) y porcentaje de los componentes de los huevos (yema, clara y cascara) y la gravedad específica $(\mathrm{g} / \mathrm{cm} 3)$. No fueron observados cambios significativos en los parámetros evaluados de acuerdo a las diferentes relaciones de valina con lisina digestible estudiadas. Se concluyó que la relación de valina digestible con lisina digestible de 0,75 en la alimentación, proporciona rendimientos satisfactorios de desempeño y calidad de huevos para codornices japonesas.

Palabras clave: Aminoácidos, codorniz japonesa, producción de huevos, valina

\section{Introdução}

A valina é um aminoácido alifático similar a leucina e a isoleucina, tanto em estrutura, como em função. Estes aminoácidos são extremamente hidrofóbicos e são quase sempre encontrados no interior de proteínas. Eles raramente são úteis em reações bioquímicas normais, mas estão relegados à função de determinar a estrutura tridimensional das proteínas devido à sua natureza hidrofóbica (Lehninger, 2006). A valina se incorpora às proteínas e às enzimas em um índice molar de $6,9 \%$ quando se compara com os outros aminoácidos (Duarte et al., 2012).

A valina é um aminoácido essencial potencialmente limitante em dietas compostas principalmente por milho e farelo de soja para aves (Han et al., 1992, Corzo et al., 2004, Thornton et al., 2006). Essa limitação é particularmente evidente para aves mais velhas quando a proteína da dieta diminui e os grãos utilizados como fonte de energia aumentam em participação na constituição da dieta. Dietas inadequadas em valina para aves não só reduziram o ganho de peso e piorou a conversão alimentar, como também determinaram anormalidades das pernas e empenamento das aves (Anderson and Warnick, 1967, Robel, 1977) (Farran and Thomas, 1992a, Farran and Thomas, 1992b). Leclercq (1998) também observou redução no desempenho de frangos de corte alimentados com dietas deficientes em valina, mas não mencionou efeito sobre o empenamento e problemas de pernas. Até o momento não há informações especificas na literatura sobre a exigência desse aminoácido para codornas de qualquer idade e espécie em experimentos realizados em condições de clima tropical como é o caso brasileiro.

Formular rações para aves visando minimizar os níveis excessivos de aminoácidos essenciais não só melhora o desempenho (Baker, 1997, Tavernari et al., 2013), como também reduz a 
excreção de nitrogênio e a poluição ambiental (De Lange, 1993).

Objetivou-se avaliar relações de valina digestível com lisina digestível em rações para codornas japonesas na fase de postura.

\section{Material e Métodos}

$\mathrm{O}$ experimento foi conduzido no setor de Avicultura do Departamento de Zootecnia da Universidade Federal de Viçosa- MG, com duração de 63 dias. Foram utilizadas 480 codornas da subespécie japonesa (Coturnix coturnix japonica) com 284 dias de idade. As aves foram distribuídas em delineamento experimental inteiramente casualizado, constituído por seis tratamentos (razão de valina digestível com lisina digestível), dez repetições e oito aves por unidade experimental.

As aves foram alojadas em gaiolas de arame galvanizado, contendo 4 divisórias de dimensões de $25 \times 34 \mathrm{~cm}$, totalizando $850 \mathrm{~cm}^{2}$. As rações experimentais foram fornecidas à vontade em comedouro do tipo calha, dividido de acordo com cada tratamento e repetição. A água também foi fornecida à vontade em bebedouro tipo nipple, sendo um bebedouro para cada duas unidades experimentais.

Formulou-se uma ração basal deficiente em valina (Tabela 1); com $18,60 \%$ de PB, $2.900 \mathrm{kcal}$ de $\mathrm{EM} / \mathrm{kg}$ de ração, suplementada com cinco níveis de L-valina $(0,051 ; 0,101 ; 0,151 ; 0,202$ e $0,252 \%$ ) em substituição ao ácido glutâmico, em equivalente proteico, correspondendo às relações de valina digestível com lisina digestível de $(0,75$; $0,80 ; 0,85 ; 0,90 ; 0,95$ e $1,00 \%)$, respectivamente permanecendo as rações isoproteicas e isocalóricas. As diferenças decorrentes do balanceamento para os equivalentes proteicos de valina e ácido glutâmico foram compensadas pelo amido.

Para atender as exigências em aminoácido digestível das codornas foram utilizadas como base as relações aminoácido digestível com lisina digestível conforme descrito por Reis (2009) para treonina, triptofano, metionina mais cistina $\mathrm{e}$ arginina. As demais relações de aminoácidos, foram conforme preconizado em NRC (1994). O nível energético utilizado foi de acordo com Moura et al. (2008), já o nível de cálcio utilizado foi de acordo com Yakout (2004). A composição $\mathrm{e}$ os valores nutricionais dos ingredientes utilizados para a formulação da dieta foram calculados valendo-se de Rostagno et al. (2005).
A dieta foi fornecida duas vezes por dia, às 8:00 e às 16:00 horas, com objetivo de evitar o desperdício de ração. Os ovos foram recolhidos e contabilizados pela manhã. $\mathrm{O}$ fornecimento de luz foi de 16 horas diárias.

Foram avaliados os seguintes parâmetros: consumo de ração, produção de ovos por ave dia, produção de ovos comercializáveis, peso do ovo, massa de ovos, conversão alimentar por massa de ovos, conversão alimentar por dúzia de ovos, variação do peso corporal, peso (g) e percentagem dos componentes dos ovos e gravidade específica.

As sobras e os desperdícios foram pesados e descontados da quantidade de ração pesada para todo período. No caso de aves mortas durante o período, o seu consumo médio foi descontado e corrigido, obtendo-se o consumo médio verdadeiro para a unidade experimental em questão.

Os ovos foram coletados diariamente às 8 horas. A produção média de ovos foi obtida computando-se diariamente todos os tipos de ovos (ovos com casca mole e sem casca) sendo expressa em porcentagem sobre a média de aves do período (ovo/ave/dia). Para determinação da produção de ovos comercializáveis foi computado diariamente o número de ovos quebrados, trincados, com casca mole e sem casca. A razão entre os ovos íntegros e sem defeitos foi expressa em percentagem para cada tratamento. Todos os ovos íntegros produzidos durante os três últimos dias de cada período experimental, em cada repetição, foram pesados e o peso total foi dividido pelo número de ovos utilizados na pesagem. O peso médio dos ovos foi multiplicado pelo número total de ovos produzidos no período experimental, obtendo-se assim a massa total de ovos. Esta massa total de ovos foi dividida pelo número total de aves por dia do período sendo expressa em gramas de ovo/ ave/ dia.

Foi avaliada a conversão alimentar por massa de ovos que foi obtida pelo consumo de ração em quilogramas dividido pela massa de ovos produzidas em quilogramas $(\mathrm{kg} / \mathrm{kg})$ e a conversão alimentar por dúzia de ovos que foi expressa pelo consumo total de ração em quilogramas dividido pela dúzia de ovos produzidos $(\mathrm{kg} / \mathrm{dz})$.

As aves de cada repetição foram pesadas ao início e ao término do experimento, para a determinação do peso inicial, peso final e variação de peso ocorrido durante o período experimental. 
Para quantificação dos componentes dos ovos foram avaliados o peso da gema, o peso do albúmen e o peso da casca do ovo. Para isso, quatro ovos de cada repetição foram coletados durante os três últimos dias de cada período experimental de maneira aleatória do total de ovos íntegros coletados.

Tabela 1. Composições das dietas experimentais para codornas japonesa na matéria natural.

\begin{tabular}{|c|c|c|c|c|c|c|}
\hline \multirow[b]{2}{*}{ Ingredientes } & \multicolumn{6}{|c|}{ Tratamentos } \\
\hline & 0,75 & 0,80 & 0,85 & 0,90 & 0,95 & 1,00 \\
\hline Milho & 59,835 & 59,835 & 59,835 & 59,835 & 59,835 & 59,835 \\
\hline Farelo de soja (45\%) & 28,024 & 28,024 & 28,024 & 28,024 & 28,024 & 28,024 \\
\hline Óleo de soja & 2,101 & 2,101 & 2,101 & 2,101 & 2,101 & 2,101 \\
\hline Calcário & 6,861 & 6,861 & 6,861 & 6,861 & 6,861 & 6,861 \\
\hline Fosfato bicálcico & 1,144 & 1,144 & 1,144 & 1,144 & 1,144 & 1,144 \\
\hline Sal comum & 0,334 & 0,334 & 0,334 & 0,334 & 0,334 & 0,334 \\
\hline Acido glutâmico & 0,400 & 0,400 & 0,400 & 0,400 & 0,400 & 0,400 \\
\hline Amido & 0,100 & 0,100 & 0,100 & 0,100 & 0,100 & 0,100 \\
\hline L-Lisina HCL (79\%) & 0,203 & 0,203 & 0,203 & 0,203 & 0,203 & 0,203 \\
\hline DL-Metionina (99\%) & 0,358 & 0,358 & 0,358 & 0,358 & 0,358 & 0,358 \\
\hline L-Triptofano (99\%) & 0,038 & 0,038 & 0,038 & 0,038 & 0,038 & 0,038 \\
\hline L-valina (99\%) & 0.000 & 0,051 & 0,101 & 0,151 & 0,202 & 0,252 \\
\hline L-arginina (99\%) & 0,069 & 0,069 & 0,069 & 0,069 & 0,069 & 0,069 \\
\hline Fenilalanina & 0,039 & 0,039 & 0,039 & 0,039 & 0,039 & 0,039 \\
\hline Cloreto de colina $(60 \%)$ & 0,100 & 0,100 & 0,100 & 0,100 & 0,100 & 0,100 \\
\hline Suplemento vitaminico ${ }^{1}$ & 0,100 & 0,100 & 0,100 & 0,100 & 0,100 & 0,100 \\
\hline Suplemento mineral $^{2}$ & 0,050 & 0,050 & 0,050 & 0,050 & 0,050 & 0,050 \\
\hline Antioxidante $^{3}$ & 0,010 & 0,010 & 0,010 & 0,010 & 0,010 & 0,010 \\
\hline Total & 100,00 & 100,00 & 100,00 & 100,00 & 100,00 & 100,00 \\
\hline \multicolumn{7}{|l|}{ Composição calculada } \\
\hline Energia metabolizável (kcal/kg) & 2,900 & 2,900 & 2,900 & 2,900 & 2,900 & 2,900 \\
\hline Proteína bruta (\%) & 18,60 & 18,60 & 18,60 & 18,60 & 18,60 & 18,60 \\
\hline Lisina digestível (\%) & 1,000 & 1,000 & 1,000 & 1,000 & 1,000 & 1,000 \\
\hline Lisina total $(\%)$ & 1,080 & 1,080 & 1,080 & 1,080 & 1,080 & 1,080 \\
\hline Metionina + cistina digestível $(\%)$ & 0,860 & 0,860 & 0,860 & 0,860 & 0,860 & 0,860 \\
\hline Treonina digestível (\%) & 0,640 & 0,640 & 0,640 & 0,640 & 0,640 & 0,640 \\
\hline Triptofano digestível (\%) & 0,240 & 0,240 & 0,240 & 0,240 & 0,240 & 0,240 \\
\hline Valina digestível (\%) & 0,750 & 0,800 & 0,850 & 0,900 & 0,950 & 1,000 \\
\hline Valina total $(\%)$ & 1,030 & 1,080 & 1,130 & 1,180 & 1,230 & 1,280 \\
\hline Isoleucina total $(\%)$ & 1,000 & 1,000 & 1,000 & 1,000 & 1,000 & 1,000 \\
\hline Cálcio $(\%)$ & 3,000 & 3,000 & 3,000 & 3,000 & 3,000 & 3,000 \\
\hline Fósforo disponível (\%) & 0,310 & 0,310 & 0,310 & 0,310 & 0,310 & 0,310 \\
\hline Sódio (\%) & 0,150 & 0,150 & 0,150 & 0,150 & 0,150 & 0,150 \\
\hline Fibra bruta $(\%)$ & 2,550 & 2,550 & 2,550 & 2,550 & 2,550 & 2,550 \\
\hline
\end{tabular}

${ }^{1}$ Composição /kg de produto: Vit. A: 12.000 .000 U.I., Vit D3: 3.600.000 U.I., Vit. E: 3.500 U.I., Vit. B1: 2.500 mg, Vit B2: 8.000 mg, Vit B6: $5.000 \mathrm{mg}$, Ácido pantotênico: $12.000 \mathrm{mg}$, Biotina: $200 \mathrm{mg}$, Vit. K: $3.000 \mathrm{mg}$, Ácido fólico: 1.500mg, Ácido nicotínico: $40.000 \mathrm{mg}$, Vit. B12: $20.000 \mathrm{mg}$, Selênio: $150 \mathrm{mg}$, Veículo q.s.p.: 1.000g; ${ }^{2}$ Composição/kg de produto: Mn: 160g Fe: 100g, Zn: 100g, Cu: 20g, Co: 2g, I:2g, Veículo q.s.p.: $1000 \mathrm{~g}$; ${ }^{3 B}$ Butil-hidróxi-tolueno, BHT (99\%).

Esses ovos foram pesados individualmente em balança com precisão de 0,001 g. Os mesmos foram identificados, e posteriormente quebrados. A gema de cada ovo foi pesada e registrada, e a respectiva casca foi lavada e seca ao ar, para obtenção do peso da casca. O peso do albúmen foi obtido pela diferença do peso do ovo menos o peso da gema mais o peso da casca. Foram obtidos e 
calculados também os valores percentuais dos componentes dos ovos.

No $16^{\circ}, 17^{\circ}, 18^{\circ}, 37^{\circ}, 38^{\circ}, 39^{\circ}, 58^{\circ}, 59^{\circ}$ e $60^{\circ}$ dias experimentais, todos os ovos íntegros coletados foram imersos e avaliados em soluções de $\mathrm{NaCl}$ com densidade variando de 1,055 a 1,090 $\mathrm{g} / \mathrm{cm}^{3}$, sendo a densidade ou peso específico dos ovos medido por meio de um densímetro com capacidade de avaliação de 1,050 à $1,100 \mathrm{~g} / \mathrm{cm}^{3}$.

Os parâmetros foram submetidos a análises estatísticas por meio do programa Sistema para Análises Estatísticas (SAEG), desenvolvido na Universidade Federal de Viçosa - UFV (2007), utilizando-se os procedimentos para análise de variância e regressão.

\section{Resultados e Discussão}

As médias referentes aos resultados de desempenho e de qualidade de ovos estão apresentadas na tabela 2 .

As relações de valina digestível com lisina digestível não influenciaram $(\mathrm{P}>0,05)$ nenhum dos parâmetros de desempenho e qualidade avaliados.

Os resultados de CR obtidos estão de acordo com os encontrados por Tavernari et al. (2013) que ao avaliarem o desempenho de galinhas poedeiras de 25 a 37 semanas de idade, submetidas a três diferentes níveis de valina $(0,84,0,90$ e $0,96 \%)$ também não encontraram diferenças significativas para o consumo de ração.

Com os resultados de CR obtidos pode-se inferir que, o aumento das razões de valina digestíveis, não foram suficientes para produzir desbalanço aminoacídico que resultasse na alteração do perfil plasmático do animal, e ativasse os mecanismos reguladores do apetite, como descrito por Harper and Benevenga (1970).

Verificou-se, que não houve influência ( $\mathrm{P}$ > $0,05)$ das razões de valina com lisina para produção de ovos/ave/dia, a razão de 0,75 de valina digestível com lisina digestível, foi suficiente para a manutenção da taxa de postura. Resultados diferentes foram encontrados por Harms and Russell (2001) que verificaram em seus estudos que quando galinhas poedeiras foram submetidas a dietas com níveis inferiores a $0,630 \%$ de valina, as mesmas tiveram um pior desempenho para produção de ovos. Isso sugere a necessidade de se avaliar relações inferiores a 0,75 de valina com lisina para codornas, para se chegar a resultados conclusivos sobre as exigências dessa ave sobre o respectivo aminoácido e sua influência na produção de ovos.

Tabela 2. Consumo de ração (CR), produção de ovos por ave por dia (POAD), produção de ovos comercializáveis (POC), peso do ovo (PO), massa de ovos (MO), conversão alimentar por massa de ovos (CAMO), conversão alimentar por dúzia de ovos (CADZ), (gema (G), albúmen (A), casca (C), gravidade especifica (GE) e variação de peso corporal (VPC) em função das relações de valina digestível com lisina digestível na ração.

\begin{tabular}{|c|c|c|c|c|c|c|c|}
\hline \multirow{2}{*}{ Parâmetros ${ }^{1}$} & \multicolumn{5}{|c|}{ Relações de valina com lisina } & \multirow[b]{2}{*}{1,00} & \multirow{2}{*}{${ }^{2} \mathrm{CV}(\%)$} \\
\hline & 0,75 & 0,80 & 0,85 & 0,90 & 0,95 & & \\
\hline CR (g/ave/dia) & 28,32 & 28,52 & 29,39 & 26,28 & 28,75 & 28,98 & 7,91 \\
\hline POAD (\%) & 84,61 & 78,55 & 81,31 & 82,97 & 81,32 & 80,81 & 12,20 \\
\hline POC (\%) & 83,65 & 77,63 & 79,73 & 82,5 & 79,75 & 79,53 & 9,23 \\
\hline $\mathrm{PO}(\mathrm{g})$ & 11,77 & 11,82 & 11,71 & 11,72 & 11,81 & 11,92 & 2,66 \\
\hline MO (g/ave/dia) & 9,96 & 9,28 & 9,51 & 9,72 & 9,60 & 9,64 & 8,91 \\
\hline $\mathrm{CA}(\mathrm{kg} / \mathrm{kg})$ & 2,84 & 2,86 & 3,10 & 2,72 & 3,02 & 2,98 & 0,17 \\
\hline CADZ (kg/dZ) & 0,403 & 0,406 & 0,430 & 0,389 & 0,429 & 0,420 & 10,75 \\
\hline $\mathrm{G}(\mathrm{g})$ & 3,56 & 3,57 & 3,56 & 3,53 & 3,58 & 3,58 & 3,04 \\
\hline $\mathrm{G}(\%)$ & 30,06 & 30,03 & 30,28 & 29,66 & 30,17 & 30,23 & 2,70 \\
\hline $\mathrm{A}(\mathrm{g})$ & 7,34 & 7,39 & 7,30 & 7,35 & 7,39 & 7,44 & 3,64 \\
\hline $\mathrm{A}(\%)$ & 61,93 & 61,85 & 61,49 & 62,23 & 61,72 & 61,68 & 1,92 \\
\hline $\mathrm{C}(\mathrm{g})$ & 0,95 & 0,97 & 0,97 & 0,96 & 0,93 & 0,96 & 3,52 \\
\hline $\mathrm{C}(\%)$ & 8,01 & 8,12 & 8,23 & 8,11 & 8,11 & 8,09 & 3,39 \\
\hline $\mathrm{GE}\left(\mathrm{g} / \mathrm{cm}^{3}\right)$ & 1,073 & 1,072 & 1,072 & 1,073 & 1,071 & 1,072 & 0,167 \\
\hline
\end{tabular}

${ }^{1}$ Não significativo $(\mathrm{p}>0,05) .{ }^{2} \mathrm{CV}=$ Coeficiente de Variação

O alto coeficiente de variação apresentado pela produção de ovos/ave/dia pode ser devido ao fato dessa variável ser gerada durante um período longo de observação 63 dias e a mesma estar 
sujeita a variações de produção que podem ser provocadas por estresse, mudanças climáticas ou mesmo o manejo diário das aves.

Os resultados para produção de ovos comercializáveis mostram que as relações de valina digestível com lisina digestível na dieta não influenciaram $(\mathrm{P}>0,05)$ a qualidade dos ovos destinados à comercialização, sendo o suficiente para a manutenção boa qualidade dos mesmos.

Não houve influência $(P>0,05)$ das relações de valina com lisina sobre o peso do ovo. Harms and Russell (2001) ao avaliarem a exigência de valina para galinhas poedeiras leves, com 39 semanas de idade verificaram melhora no peso do ovo de aves alimentadas com ração contendo $0,655 \%$ de valina em comparação aqueles provenientes de aves que receberam ração contendo $0,630 \%$ de valina, no presente experimento tal fato não pode ser comprovado uma vez que o nível mínimo de valina testado nas rações foi de 0,750 . Constatou-se, que não houve influência $(P>0,05)$ das relações de valina sobre a massa de ovos produzida. Esses resultados também discordam de Tavernari et al. (2013) que encontraram diferenças significativas em seus estudos para massa de ovo. Os autores observaram efeito linear desse parâmetro, conforme se elevou os níveis de valina nas dietas.

Coon and Zhang (1999) sugeriram exigência diária de $680 \mathrm{mg}$ de valina digestível para galinhas poedeiras ou $13,2 \mathrm{mg}$ de valina digestível/g de massa de ovo. Nesse trabalho sugere-se $21,3 \mathrm{mg}$ de valina digestível/g de massa de ovo para adequada produção de ovos de codornas japonesas, entretanto como esse valor foi calculado pela menor razão estudada, $(0,75)$; pode ser que a exigência real desses animais seja menor que a sugerida.

As diferentes relações de valina digestível não influenciaram $(\mathrm{P}>0,05)$ em nenhum dos componentes dos ovos avaliados, assim sendo, a razão de 0,75 de valina digestível com lisina atendeu de maneira satisfatória cada variável estudada.

Nenhum dado a respeito da influência das relações de valina com lisina ou níveis de valina na dieta sobre os parâmetros de componentes dos ovos foi encontrado na literatura para possível comparação. Entretanto pode-se inferir pelos resultados obtidos, que a ração contendo a razão de 0,75 de valina com lisina foi capaz de fornecer suporte para que a ave não tivesse a qualidade interna e externa dos ovos comprometida. A partir dos resultados médios, não se verificou influência das diferentes razões de valina sobre a mudança de peso (ganho e/ou perda) das codornas.

A valina é um importante aminoácido para a deposição proteica corporal, e quando se oferece as aves dietas com uma quantidade inferior ao exigido pelas mesmas, uma variação de peso corporal é esperada. No presente estudo a razão de 0,75 de valina com lisina foi capaz de prover as necessidades diárias das codornas, sem que houvesse redução significativa no peso corporal e consequentemente no desempenho produtivo.

As diferentes razões de valina não influenciaram $(P>0,05)$ a gravidade específica do ovo o que sugere, que a relação de 0,75 de valina com lisina atendeu satisfatoriamente a qualidade da casca do ovo. Este resultado contribuiu para que não houvesse diferença significativa na produção de ovos comercializáveis. Não foi encontrada na literatura revisada, nenhuma referência sobre razões de valina com lisina ou níveis de valina na dieta e sua correlação com a gravidade especifica do ovo, sendo esse um importante parâmetro para se avaliar a qualidade da casca e a qualidade interna do ovo.

De acordo com todos os parâmetros avaliados, o fornecimento de uma ração contendo, a razão de 0,75 de valina digestível com lisina digestível foi o suficiente para se alcançar resultados satisfatórios, tanto de desempenho quanto de qualidade dos ovos de codorna.

\section{Conclusões}

Os animais que receberam a dieta com uma relação de 0,75 de valina digestível com lisina digestível correspondente a um consumo diário de 212,4 mg desse aminoácido, obtiveram resultados similares aos encontrados nas relações superiores, sugerindo-se assim o valor de 0,75 como referência.

\section{Agradecimentos}

À Coordenação de Aperfeiçoamento Pessoal de Nível Superior - CAPES, pela concessão da bolsa de estudos.

\section{Referências Bibliográficas}

Anderson, J. O. \& Warnick, R. E. 1967. Gross abnormalities in chicks fed amino acid deficient diets. Poultry Science, 46, 856-862. 
Baker, D. H. 1997. Ideal amino acid profiles for swine and poultry and their applications in feed formulation. Biokyowa Technical Review, 9.

Coon, C. \& Zhang, B. 1999. Ideal amino acid profile for layers examined. Feedstuffs, 71, 1315.

Corzo, A., Moran, E. T. \& Hoehler, D. 2004. Valine needs of male broilers from 42 to 56 days of age. Poultry Science, 83, 946-951.

De Lange, C. F. M. 1993. Formulation of diets to minimize the contribution of livestock to environmental pollution. Proceedings of the Arkansas Nutrition Conference. Fayetteville.

Duarte, K. F., Junqueira, O. M., Filardi, R., Siqueira, A., JC, Garcia, E. A. \& Laurentiz, A. 2012. Exigências em treonina para frangos de corte de 22 a 42 dias de idade. Revista Brasileira de Zootecnia, 41, 72-79.

Farran, M. T. \& Thomas, O. P. 1992a. Valine deficiency. 1. The effect of feeding a valinedeficient diet during the starter period on performance and feather structure of male broiler chicks. Poultry Science, 71, 1879-1884.

Farran, M. T. \& Thomas, O. P. 1992b. Valine deficiency. 2. The effect of feeding a valinedeficient diet during the starter period on performance and leg abnormality of male broiler chicks. Poultry Science, 71, 1885-1890.

Han, Y., Suzuki, H., Parsons, C. M. \& Baker, D. H. 1992. Amino acid fortification of a lowprotein corn and soybean meal diet for chicks. Poultry Science, 71, 1168-1178.

Harms, R. H. \& Russell, G. B. 2001. Evaluation of valine requirement of the commercial layer using a corn-soybean meal basal diet. Poultry Science, 80, 215-218.

Harper, A. E. \& Benevenga, N. J. 1970. Effects of disproportionate amounts of amino acids. Phsyological Reviews, 50, 428-547.

Leclercq, B. 1998. Lysine: Specific effects of lysine on broiler production: comparison with threonine and valine. Poultry Science, 77, 118123.

Lehninger, N. D. L. 2006. Principios de bioquímica. São Paulo.

Moura, G. S., Toledo , S. L. B., Donzele, J. L., Hosoda, L. R., Miranda, G. P. \& Angelini, M.
S. 2008. Dietas de diferentes densidades energéticas mantendo constante a relação energia metabolizável: nutrientes para codornas japonesas em postura. Revista Brasileira de Zootecnia, 37, 1628-1633.

NRC. 1994. Nutrients Requirements of Poultry, 7th rev. edn. Natl. Acad. Press, Washington, DC., Washington.

Reis, R.S.; Barreto, S.L.T.; Medina, P.M. et al. Desempenho de codornas japonesas alimentadas com dietas contendo diferentes relações de metionina mais cistina digestível com lisina digestível. 2009. Sociedade Brasileira de Zootecnia.

Robel, E. J. 1977. A feather abnormality in chicks fed diets deficient in certain amino acids. Poultry Science, 56, 1968-1971.

Rostagno, H. S., Albino, L. F. T., Donzele, J. L., Gomes, P. C., Oliveira, R., Lopes, D. C., Ferreira, A. S., Barreto, S. \& Euclides, R. F. 2005. Composição de alimentos e exigências nutricionais, 2 edn. Universidade Federal de Viçosa, Viçosa.

Tavernari, F. C., Lelis, G. R., Vieira, R. A., Rostagno, H. S., Albino, L. F. T. \& Oliveira Neto, A. R. 2013. Valine needs in starting and growing Cobb (500) broilers. Poultry Science, 92, 151-157.

Thornton, S. A., Corzo, A., Pharr, G. T., Dozier, W. A., Miles, D. M. \& Kidd, M. T. 2006. Valine requirements for immune and growth responses in broilers from 3 to 6 weeks of age. British Poultry Science, 47, 190-199.

Yakout, H. M. 2004. Calcium and phosphorus requirements growing Japanese quail hens during the early production period. Egyptian Poultry Science Journal, 23, 617-628.

\section{Article History:}

Received 9 December 2016

Accepted 23 January 2017

Available on line 20 February 2017

License information: This is an open-access article distributed under the terms of the Creative Commons Attribution License 4.0, which permits unrestricted use, distribution, and reproduction in any medium, provided the original work is properly cited 